\title{
Curva de maturação e estimativa do teor de sólidos solúveis e acidez total em função de graus-dia: Uva IAC 138-22 'Máximo'
}

\author{
Mário José Pedro Júnior (*); José Luiz Hernandes; Gabriel Constantino Blain; \\ Ludmila Bardin-Camparotto \\ (') Instituto Agronômico (IAC), Caixa Postal 28, 13012-970 Campinas (SP), Brasil. \\ (*) Autor correspondente: mpedro@iac.sp.gov.br
}

Recebido: 9/dez./2013; Aceito: 12/fev./2014

\begin{abstract}
Resumo
Devido à crescente importância de uvas para vinho no estado de São Paulo realizou-se a caracterização da curva de maturação da IAC 138-22 'Máximo', enxertada sobre o porta-enxerto IAC 766 Campinas e conduzida no sistema de espaldeira alta em safras de verão e de inverno. Os valores do teor de sólidos solúveis (TSS) foram superiores durante as safras de inverno (17,4 ${ }^{\circ} B r i x$ a $17,5^{\circ}$ Brix) em comparação às de verão (14,2 ${ }^{\circ}$ Brix a 15,6 ${ }^{\circ}$ Brix). A acidez titulável total (ATT) também apresentou maiores valores na safra de inverno. Verificou-se que a relação entre TSS e ATT e o acúmulo de graus-dia a partir do início de maturação (pintor) podem ser descritos com base em equações polinomiais de segunda ordem.
\end{abstract}

Palavras-chave: uva para vinho, teor de açúcar, poda extemporânea, safra de inverno.

\section{Maturation curve and estimates of sugar content and titratable acidity as a function of degree-days: IAC 138-22 'Máximo' winegrape}

\section{Abstract}

The increasing importance of grape production for wine purposes in the State of São Paulo (Brazil) motivated the development of a field trial aiming at characterizing the maturation curve during summer and winter seasons for the grapevine IAC 138-22 'Máximo' grafted on the rootstock IAC 766 'Campinas' and trellised with upright branches. The total soluble solids (TSS) values were higher during the winter growing season (17.4 to $17.5^{\circ}$ Brix) when compared to the summer growing season (14.2 to $15.6^{\circ}$ Brix). The titratable acidity (ATT) was also higher during the winter growing season. Also, polynomial equations of second degree can be used to estimate the TSS and ATT as a function of accumulated degree-days starting at the beginning of maturation (véraison).

Key words: grapevine, total soluble solids, winter cycle.

As curvas de maturação de cultivares de uva para vinho têm sido determinadas a fim de aprofundar-se o conhecimento do desenvolvimento das cultivares nas diferentes regiôes ecológicas do país (Assis et al., 2011; Chavarria et al., 2010; Manfroi et al., 2004; Sato et al., 2011). A cultivar de uva para vinho Máximo vem gradativamente ocupando áreas de cultivares mais tradicionais na região vitícola do leste paulista (Camargo et al., 2011) em função do maior interesse do viticultor no turismo rural (Verdi et al., 2010), devido à crescente procura pelo vinho artesanal. Essa cultivar tem sido avaliada sob diferentes aspectos como: produção em diferentes porta-enxertos (Terra et al., 1990); potencial de acúmulo de açúcares (Hernandes et al., 2010) e comportamento em regime de produção durante safras sequenciais de verão e de inverno (Santos et al., 2011a). Considerando que a 'Máximo' tem sido utilizada, na porção leste do estado de Sáo Paulo, principalmente para a produção de vinhos artesanais (Hernandes et al., 2010), torna-se necessária a avaliação do seu potencial de acúmulo de açúcares sob uma condição climática úmida, uma vez que a colheita, para a época normal de poda (julhoagosto), ocorre em meses chuvosos (dezembro-janeiro), não favoráveis ao acúmulo de açúcares nos frutos.

É também interessante ressaltar que a técnica da poda extemporânea tem sido utilizada a fim de permitir a colheita em meses mais secos (junho-julho), possibilitando obtenção de maiores teores de sólidos solúveis. Nesse 
sentido, Mota et al. (2010) relataram que a alteração do ciclo de produção para colheita em meses mais secos melhora a qualidade do mosto, principalmente o teor de sólidos solúveis e a acidez. Em diferentes estados brasileiros, a técnica da poda extemporânea tem sido utilizada com sucesso. Como exemplos, citam-se os trabalhos de Mota et al. (2010) em Minas Gerais, com cultivares de uvas para vinho fino, Jubileu et al. (2010) no Paraná, com as cultivares Cabernet Sauvignon e Alicante, e Regina et al. (2011) no nordeste do estado de Sáo Paulo, com uvas viníferas em regime de dupla poda. Esses resultados, obtidos a partir da poda extemporânea sob diferentes condiçôes climáticas regionais, motivam a caracterização da curva de maturação da 'Máximo' durante as safras de verão e de inverno na regiáo produtora de Jundiaí (SP).

Além disso, dada a importância do conhecimento do acúmulo de sólidos solúveis (TSS) e da diminuição da acidez total (ATT) durante o processo de maturação das uvas, diversos autores desenvolveram equaçóes de estimativa desses parâmetros, utilizando modelos de regressão polinomial de primeira, segunda e terceira ordem, nos quais as variáveis independentes foram: número de dias após a poda (Assis et al., 2011; Sato et al., 2009; Yamamoto et al., 2011); data do calendário (Chavarria et al., 2010; Manfroi et al., 2004); dias após o florescimento (Roberto et al., 2004); e dias após a maturação (Silva et al., 2008). Entretanto, a relação, ou covariação, entre TSS e/ou ATT com datas de calendário ou número de dias após florescimento ou maturação pode, evidentemente, variar em função das condiçôes de temperatura de cada regiáo e período. Assim, os objetivos deste trabalho foram (i) caracterizar as curvas de acúmulo do teor de sólidos solúveis e de diminuição da acidez total para a cultivar de uva para vinho IAC 138-22 'Máximo' e (ii) desenvolver equaçóes de estimativa desses parâmetros baseadas no acúmulo de graus-dia após o início da maturação (pintor) para as safras de verão e de inverno.

O experimento foi conduzido em vinhedo da uva para vinho IAC 138-22 'Máximo' situado no município de Jundiaí (SP) e localizado na latitude: $23^{\circ} 12^{\prime}$ sul; longitude: $46^{\circ} 53^{\prime}$ oeste e altitude média de $700 \mathrm{~m}$. A região está, segundo a classificação climática de Köppen, situada numa área de transição entre $\mathrm{Cfa}$ (clima mesotérmico úmido com temperatura do mês mais quente superior a $22^{\circ} \mathrm{C}$ ), para as áreas mais baixas, e $\mathrm{Cfb}$ (clima mesotérmico úmido com temperatura do mês mais quente inferior a $22^{\circ} \mathrm{C}$ ), para as mais elevadas. As plantas foram enxertadas sobre o portaenxerto IAC-766 'Campinas' e o vinhedo, com oito anos de idade, foi conduzido em espaldeira alta com quatro fios de arame para suporte dos ramos verticais. As videiras foram plantadas no espaçamento $2 \times 1 \mathrm{~m}$ e os tratos culturais (poda, desponte, desnetamento) e fitossanitários (controle de doenças fúngicas) foram feitos como recomendados para a regiâo. As datas de poda foram respectivamente: 12/8/2010 e 25/8/2011 para as safras de verão e 17/2/2011 e 6/2/2012 para as safras de inverno.

O delineamento experimental foi inteiramente casualizado. O mosto foi obtido por meio da coleta semanal de 100 bagas por amostragem realizada desde o início da maturação (pintor) até a colheita. A acidez titulável foi obtida por titulação do suco com solução padronizada de $\mathrm{Na} \mathrm{OH}$ $0,1 \mathrm{~N}$, adotando-se como ponto final da titulaçáo o $\mathrm{pH}=8,2$, utilizando-se pHmetro de bancada. O teor de sólidos solúveis foi determinado por refratômetro manual com escala de 0-32 ${ }^{\circ}$ Brix. As medições da temperatura do ar foram feitas em ambiente externo (posto meteorológico), sendo os sensores (Campbell HMP 45C) acoplados a sistema automático de aquisição de dados (Campbell Scientific - CR 10X) programado para amostragens a cada minuto, tendo sido armazenados os valores extremos (temperatura máxima e mínima) diários. As mediçôes foram feitas desde a data de poda até a colheita tanto para a safra de verão quanto para a de inverno.

Os valores de TSS e ATT obtidos durante a fase de maturação foram comparados aos graus-dia acumulados a partir da data de início de maturação (pintor), utilizando-se a temperatura base de $10{ }^{\circ} \mathrm{C}$ (Hidalgo, 1980; Roberto et al., 2005). Com base nos trabalhos de Assis et al. (2011), Chavarria et al. (2010), Manfroi et al. (2004), Roberto et al. (2004), Sato et al. (2009), Silva et al. (2008), Yamamoto et al. (2011), as estimativas do TSS e da ATT em funçáo dos graus-dia foram feitas a partir da análise de regressão, considerando-se equaçốes polinomiais de primeira a terceira ordem. A escolha do melhor modelo foi feita com base no coeficiente de correlação $\left(R^{2}\right)$. A estimativa dos parâmetros das equaçóes de regressão foi feita por meio do método dos quadrados mínimos.

\section{EVOLUÇÃO DA MATURAÇÃO}

Na figura 1 é apresentada a variação do teor de sólidos solúveis e da acidez total para as safras de verão (2010 e 2011) e de inverno (2011 e 2012). Verifica-se que, durante as safras de verão, os valores de TSS obtidos na colheita foram $14,2^{\circ}$ Brix e $15,6^{\circ}$ Brix respectivamente para as safras de 2010 e 2011 (Figura 1). Para as safras de inverno foram obtidos valores superiores de TSS, $17,4^{\circ}$ Brix e $17,5^{\circ}$ Brix respectivamente para as safras de 2011 e 2012 (Figura 1). Os menores valores de TSS obtidos para as safras de verão são devidos ao fato de a colheita ocorrer em plena época chuvosa, enquanto a colheita da safra de inverno (meses de junho e julho) coincide com a estação seca regional. Essa característica da maturação de uvas também foi observada por diferentes autores, que têm recomendado a poda extemporânea para obtenção de maiores valores de TSS (Jubileu et al., 2010; Mota et al., 2010; Regina et al., 2011) em função de a colheita ser efetuada durante época do ano em que as condiçōes climáticas são mais favoráveis para a maturação da uva. 

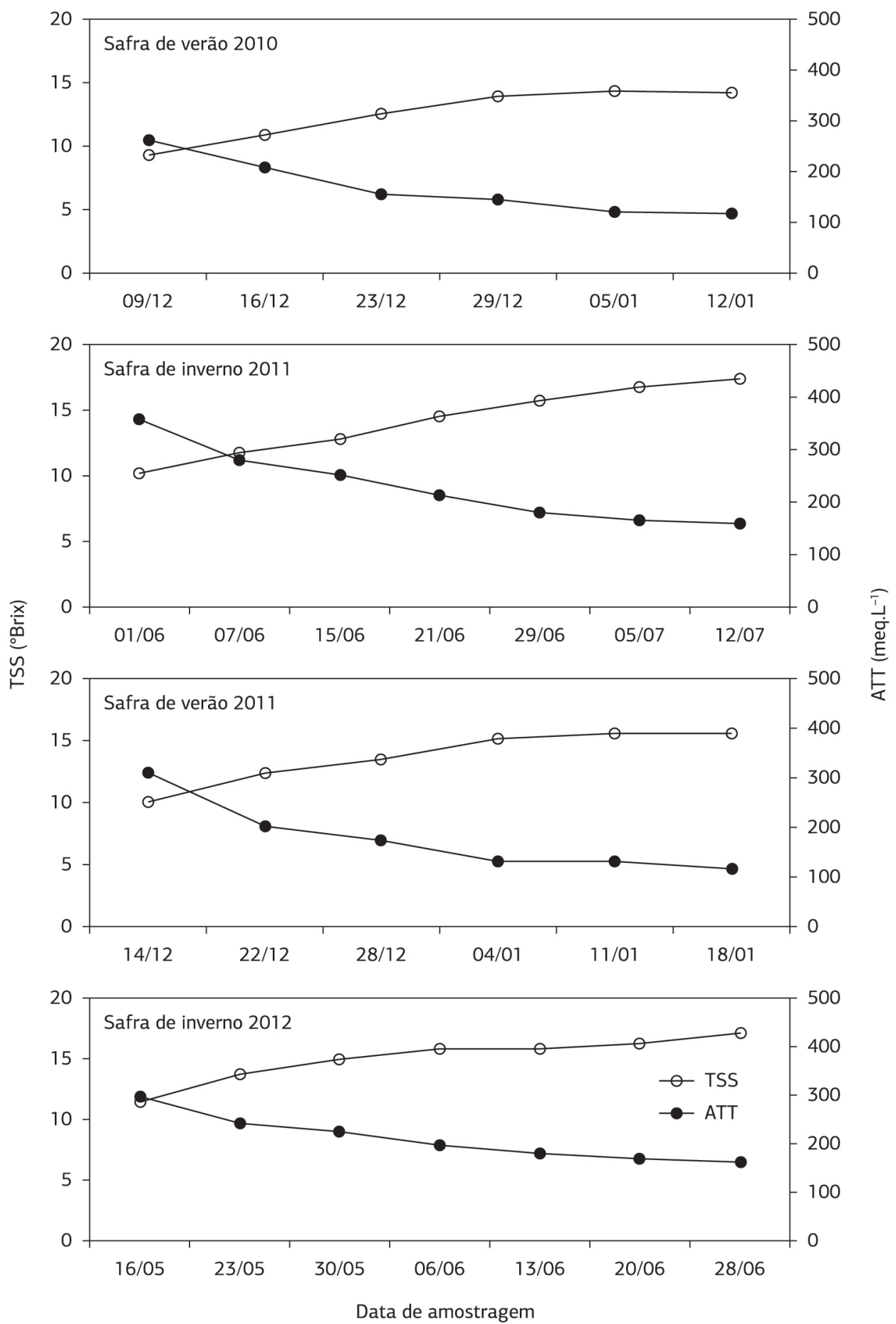

Figura 1. Variação do teor de sólidos solúveis (TSS) e da acidez titulável total (ATT) para a cultivar de uva IAC 138-22 'Máximo’ durante safras de verão e de inverno em Jundiaí (SP).

Os valores de TSS obtidos neste experimento durante a safra de inverno foram inferiores aos relatados por Hernandes et al. (2010) para a época de verão e semelhantes aos apresentados por Santos et al. (2011a) para a época de inverno. Ainda pela figura 1 observa-se que os valores de TSS durante as safras de verão de 2010 e de 2011 atingiram estabilidade a partir de (aproximadamente) $14^{\circ}$ Brix a $15^{\circ}$ Brix, enquanto para as safras de inverno de 2011 e de 2012 essa característica ocorreu na faixa de $17^{\circ}$ Brix (aproximadamente, 130 a 140 dias após a poda). Em relação à acidez total titulável (Figura 1) foi observada uma diminuição dos valores até a data de colheita, com 116 meq. $\mathrm{L}^{-1}$ e 117 meq. $\mathrm{L}^{-1}$ para as safras de verão e com 157 meq. $\mathrm{L}^{-1}$ e 159 meq. $\mathrm{L}^{-1}$ para as safras de inverno. As diferenças entre as safras de verão e de inverno podem estar relacionadas à influência da temperatura no fenômeno da 

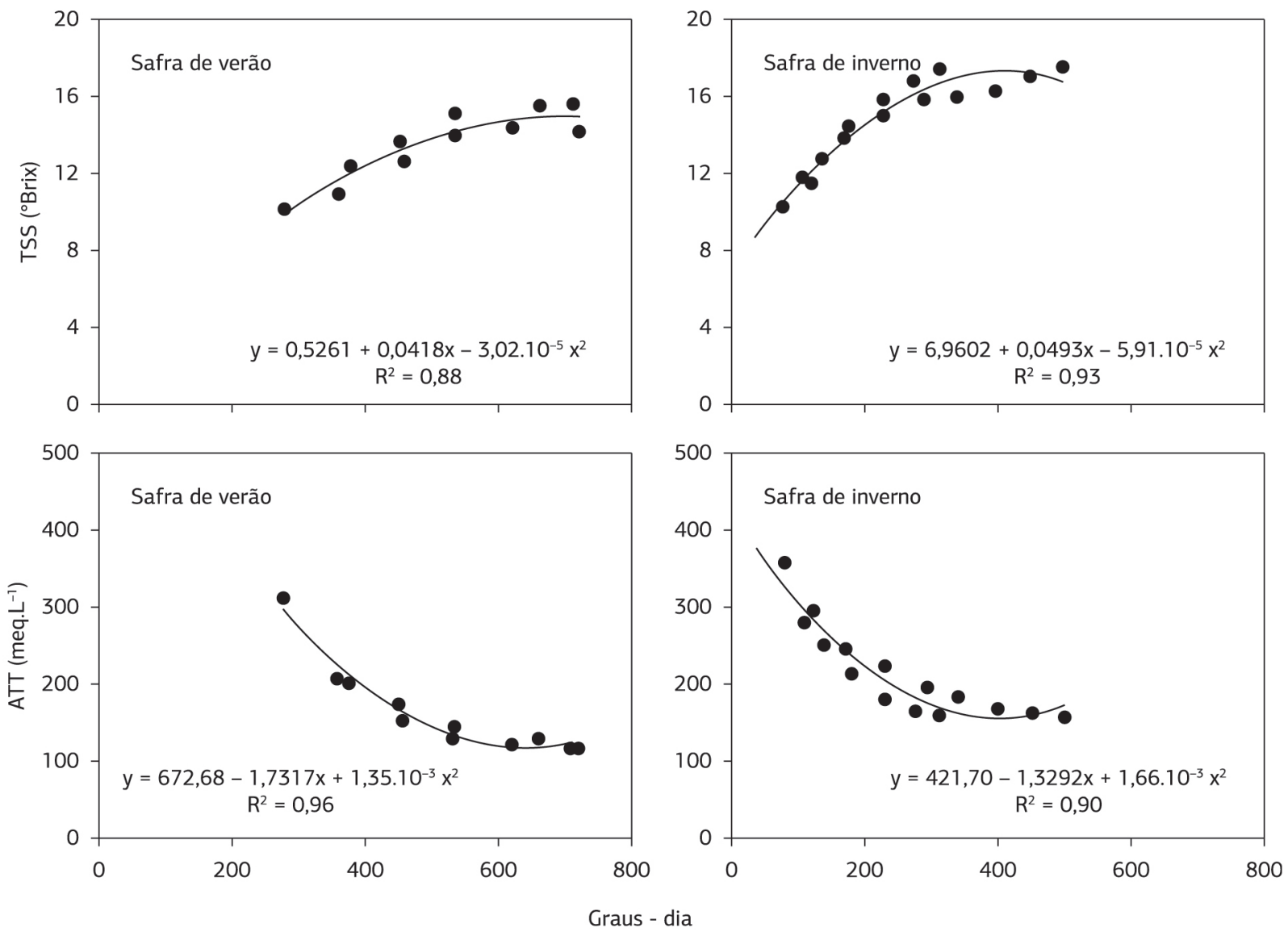

Figura 2. Relação entre o teor de sólidos solúveis (TSS) e acidez titulável total (ATT) e graus-dia acumulados a partir do início da maturação (pintor) para a cultivar de uva IAC 138-22 'Máximo' durante as safras de verão e de inverno em Jundiaí (SP).

combustâo respiratória, pois como salientado por Mota et al. (2006), em regiōes quentes, onde a maturação ocorre sob temperaturas elevadas, os substratos para a respiraçáo celular são os ácidos. Os valores de ATT obtidos durante a safra de verão no presente trabalho foram semelhantes aos relatados por Santos et al. (2011b) para a cultivar Syrah na região de Jundiaí (SP).

\section{RELAÇÃO TSS, ATT E GRAUS-DIA}

$\mathrm{Na}$ figura 2 são apresentadas as relaçóes entre os valores de graus-dia acumulados a partir da data de início de maturaçáo e os valores observados de TSS e ATT para a cultivar Máximo durante as safras de verão e de inverno. As equaçóes que melhor se ajustaram aos dados foram as polinomiais de segundo grau:

$y=a+b x+c x^{2}$

em que: y é o TSS ( ${ }^{\circ}$ Brix) ou ATT (meq.L $\left.{ }^{-1}\right)$; x é o total de graus-dia acumulados a partir da data de início da maturação (pintor); e a, b e c são coeficientes da equaçáo.

Equaçôes polinomiais de grau 2 foram também relatadas por Yamamoto et al. (2011) para relacionar ATT e dias após a poda para a BRS Clara, e por Silva et al. (2008) para Syrah, enquanto Sato et al. (2009) utilizaram polinomiais de grau 3 para a Isabel sobre diferentes porta-enxertos ao relacionar TSS e ATT com número de dias após o florescimento. Por outro lado, diferentes autores têm utilizado a regressão linear simples para relacionar TSS e ATT com dias após a poda, data de calendário (Manfroi et al., 2004), dias após florescimento e dias após o início de maturação.

Os valores dos coeficientes de determinação foram elevados, variando entre 0,88 (TSS, safra de verão) e 0,96 (ATT, safra de verão), indicando a possibilidade de utilização do acúmulo de graus-dia para estimativa de TSS e ATT para a 'Máximo' nas safras de verão e de inverno. Os valores de $\mathrm{R}^{2}$ (Figura 2) foram da mesma ordem de grandeza dos relatados para Tannat (Roberto et al., 2004) Cabernet franc (Manfroi et al., 2004) e BRS Clara (Yamamoto et al., 2011). Entretanto, deve-se ressaltar que as equações polinomiais de grau 2 utilizadas no presente estudo apresentam, evidentemente, um ponto de inflexão a partir do qual não podem mais ser utilizadas. Para as estimativas de TSS durante as safras de verão e inverno, essa inflexão ocorre após o acúmulo de 692 GDD e 407 GDD, respectivamente. Para as estimativas de ATT, o ponto de mínimo ocorre em 620 GDD (verão) e 392 GDD (inverno). 
Os resultados obtidos neste estudo permitem concluir que a cultivar de uva para vinho Máximo tende a apresentar, durante a safra de inverno, acúmulo do teor de sólidos solúveis superior ao observado durante a safra de verão. No presente experimento foram observados $17,4^{\circ} \mathrm{Brix}$ e $17,5^{\circ}$ Brix (safra de inverno) e $14,2^{\circ}$ Brix e $15,6^{\circ}$ Brix (safra de verão). A acidez total titulável tende também a ser superior durante a safra de inverno em comparação à de verão. Os resultados permitem concluir, ainda, que, o acúmulo de graus-dia após a data de início de maturação pode ser utilizado para estimativa do teor de sólidos solúveis e da acidez total titulável.

\section{AGRADECIMENTOS}

Ao Conselho Nacional de Desenvolvimento Científico e Tecnológico (CNPq), pela bolsa de produtividade concedida ao Dr. Mário José Pedro Júnior e à Fundação de Amparo à Pesquisa do Estado de Sáo Paulo (FAPESP), pela bolsa de pós-doutorado, concedida à Dr. ${ }^{a}$ Ludmila Bardin-Camparotto.

\section{REFERÊNCIAS}

ASSIS, A.M.; YAMAMOTO, L.Y.; SOUZA, F.S.; BORGES, R.S.; ROBERTO, S.R. Evolução da maturação e características-físico químicas e produtivas das videiras 'BRS Carmem' e 'Isabel'. Revista Brasileira de Fruticultura, volume especial, p.493-498, 2011.

CAMARGO, U.A.; TONIETTO, J.; HOFFMANN, A. Progressos na viticultura brasileira. Revista Brasileira de Fruticultura, vol.33, p.144-149, 2011.

CHAVARRIA, G.; SANTOS, H.P.; ZANUS, M.C.; MARODIN, G.A.B.; CHALAÇA, M.Z.; ZORGAN, C. Maturação de uvas Moscato Giallo sob cultivo protegido. Revista Brasileira de Fruticultura, v.32, p.151-160, 2010. http://dx.doi.org/10.1590/ S0100-29452010005000014

HERNANDES, J.L.; PEDRO JÚNIOR, M.J.; SANTOS, A.O.; TECCHIO, M.A. Fenologia e produção de cultivares americanas e híbridas de uvas para vinho, em Jundiaí-SP. Revista Brasileira de Fruticultura, v.32, p.135-142, 2010. http://dx.doi.org/10.1590/ S0100-29452010005000040

HIDALGO, L. Caracterizacion macrofisica del ecossistema medioplanta em los viñedos espańoles. Instituto Nacional de Investigaciones Agrarias. Madrid, 1980. 255p. (Serie Producion Vegetal, n.29)

JUBILEU, B.S.; SATO, A.J.; ROBERTO, S.R. Caracterização fenológica e produtiva das videiras 'Cabernet Sauvignon' e 'Alicate' (Vitis vinifera L.) produzidas fora de época, no norte do Paraná. Revista Brasileira de Fruticultura, v.32, p.451-462, 2010. http://dx.doi.org/10.1590/ S0100-29452010005000051

MANFROI, L.; MIELE, A.; RIZZON, L.A.; BARRADAS, C.I.N.; SOUZA, P.V.D. Evolução da maturação da uva Cabernet Franc conduzida no sistema lira aberta. Ciência e Agrotecnologia, v.28, p.306313, 2004. http://dx.doi.org/10.1590/S1413-70542004000200009
MOTA, R.V.; REGINA, M.A.; AMORIM, D.A.; FÁVERO, A.C. Fatores que afetam a maturação e a qualidade da uva para vinificação. Informe Agropecuário, v.27, p.56-64, 2006.

MOTA, R.V.; SILVA, C.P.C.; FAVERO, A.C.; PURGATTO, E.; SHIGA, T.M.; REGINA, M.A. Composição físico-química de uvas para vinho fino em ciclos de verão e inverno. Revista Brasileira de Fruticultura, v.32, p.1127-1137, 2010. http://dx.doi.org/10.1590/ S0100-29452011005000001

REGINA, M.A.; MOTA, R.V.; FAVERO, A.C.; SHIGA, T.M.; SILVA, L.H.J; SOUZA, W.C.; NOVELLI, F.A.D.; SOUZA, C.R. Caracterização físico-química de uvas viníferas cultivadas em regime de dupla-poda no nordeste do estado de Sáo Paulo. Revista Brasileira de Viticultura e Enologia, v.3, p.84-92, 2011.

ROBERTO, S.R.; SATO, A.J.; BRENNER, E.A.; JUBILEU, B.S.; SANTOS, C.E.; GENTA, W. Caracterização da fenologia e exigência térmica (graus-dias) para a uva 'Cabernet Sauvignon' em zona subtropical. Acta Scientiarum, Agronomy, v.27, p.183-187, 2005.

ROBERTO, S.R.; YAMASHITA, F. BRENNER, E.A.; SATO, A.J.; SANTOS, C.E.; GENTA, W. Curvas de maturação da uva 'Tannat' (Vitis vinifera L.) para a elaboraçáo de vinho tinto. Semina: Ciências Agrárias, v.25, p.173-178, 2004.

SANTOS, A.O.; HERNANDES, J.L.; PEDRO JÚNIOR, M.J.; PEREIRA, S.E. Composiçáo da produçáo e qualidade da uva em videira cultivada sob dupla poda e regime microclimático estacional contrastante. Revista Brasileira de Fruticultura, v.33, p.1135-1154, 2011a. http://dx.doi.org/10.1590/S0100-29452011000400012

SANTOS, A.O.; HERNANDES, J.L.; PEDRO JÚNIOR, M.J.; ROLIM, G.S. Parâmetros fitotécnicos e condiçóes microclimáticas para videira vinífera conduzida sob dupla poda sequencial. Revista Brasileira de Engenharia Agrícola e Ambiental, v.15, p.1251-1256, 2011b. http://dx.doi.org/10.1590/S1415-43662011001200006

SATO, A.J.; JUBILEU, B.S.; ASSIS, A.M.; ROBERTO, S.R. Fenologia, produção e composição do mosto da 'Cabernet Sauvignon' e 'Tannat' em clima subtropical. Revista Brasileira de Fruticultura, v.33, p.491499, 2011. http://dx.doi.org/10.1590/S0100-29452011005000079

SATO, A.J.; SILVA, B.J.; BERTOLUCCI, R.; CARIELO, M.; GUIRAND, M.C.; FONSECA, I.C.B.; ROBERTO, S.R. Evolução da maturação e características físico-químicas de uvas da cultivar Isabel sobre diferentes porta-enxertos na Região Norte do Paraná. Semina: Ciências Agrárias, v.30, p.11-20, 2009.

SILVA, F.C.C.; VIANA, A.P.; SILVA, M.G.O.; OLIVEIRA, J.B.; GOMES FILHO, A. Caracterização química e determinação dos estádios fenológicos de variedades de videiras cultivadas no Norte Fluminense. Revista Brasileira de Fruticultura, v.30, p.38-42, 2008. http://dx.doi.org/10.1590/S0100-29452008000100009

TERRA, M.M.; PIRES, E.J.P; PASSOS, I.R.S.; SANTOS, R.R.; POMMER, C.V.; SILVA, A.C.P; RIBEIRO, I.J.A. Porta-enxertos para o cultivar Máximo IAC 138-22 de uvas de vinho em Monte Alegre do Sul, SP. Bragantia, v.49, p.363-369, 1990. http://dx.doi. org/10.1590/S0006-87051990000200015

VERDI, A.V.; OTANI, M.N.; MAIA, M.L.; FREDO, C.E.; HERNANDES, J.L. Caracterização sócio-econômica e perfil produtivo da produçáo de uva e vinho artesanal no município de Jundiaí, estado de São Paulo. Informações Econômicas, v.40, p.23-33, 2010.

YAMAMOTO, L.Y.; ASSIS, A.M.; MORAIS, H.; SOUZA, F.S.; MIOTTO, L.C.V.; SATO, A.J.; SOUZA, R.T.; ROBERTO, S.R. Evolução da maturação da uva 'BRS Clara' sob cultivo protegido durante a safra fora de época. Bragantia, v.70, p.825-831. 2011. http://dx.doi.org/10.1590/S0006-87052011000400014 